CYSTIC FIBROSIS

\title{
Association of tumour necrosis factor alpha variants with the CF pulmonary phenotype
}

\author{
J Yarden, D Radojkovic, K De Boeck, M Macek Jr, D Zemkova, V Vavrova, R Vlietinck, \\ J-J Cassiman, H Cuppens
}

Thorax 2005;60:320-325. doi: 10.1136/thx.2004.025262

See end of article for authors' affiliations

Correspondence to: Dr H Cuppens, Department for Human Genetics, KULeuven, Herestraat 49 O\&N6, 3000 Leuven, Belgium; harry.cuppens@ med.kuleuven.ac.be

Received 19 March 2004 Accepted 25 October 2004
Background: The pulmonary phenotype in patients with cystic fibrosis (CF), even in those with the same CF transmembrane conductance regulator (CFTR) genotype, is variable and must therefore be influenced by secondary genetic factors as well as environmental factors. Possible candidate genes that modulate the CF lung phenotype may include proinflammatory cytokines. One such protein is tumour necrosis factor $\alpha$ (TNF $\alpha$ ), a member of the immune system.

Methods: Three polymorphic loci in the promoter $(-851 \mathrm{c} / \mathrm{t},-308 \mathrm{~g} / \mathrm{a},-238 \mathrm{~g} / \mathrm{a})$ and one polymorphic locus in intron 1 ( $+691 \mathrm{~g}$ ins/del) of the TNF $\alpha$ gene were typed by a single nucleotide primer extension assay in CF patients and healthy controls. Spirometric data and first age of infection with Pseudomonas aeruginosa were collected retrospectively from patients' medical records.

Results: An association was found between the TNF $\alpha+691 \mathrm{~g}$ ins $/$ del polymorphic locus and severity of CF lung disease. Patients heterozygous for $+691 \mathrm{~g}$ ins and $+691 \mathrm{~g}$ del were more likely to have better pulmonary function (mean (SD) forced expiratory volume in 1 second $\left(\mathrm{FEV}_{1}\right) 79.7$ (12.8)\% predicted) than patients homozygous for $+691 \mathrm{~g}$ ins (mean (SD) FEV 67.5 (23.0)\% predicted; $p=0.008$, mean difference $12.2 \%, 95 \% \mathrm{Cl} 3.5$ to 21.0 ). Also, patients heterozygous for $+691 \mathrm{~g}$ ins and $+691 \mathrm{~g}$ del were more likely to have an older first age of infection with $P$ aeruginosa (mean (SD) 11.4 (6.0) years) than patients homozygous for $+691 \mathrm{~g}$ ins (mean (SD) $8.3(4.6)$ years; $p=0.018$, mean difference 3.1 years, $95 \% \mathrm{Cl} 0.5$ to 5.6). An association was also found with the $-851 \mathrm{c} / \mathrm{t}$ polymorphic locus. In the group of patients with more severe $\mathrm{FEV}_{1} \%$ predicted, a higher proportion of patients were homozygous for the $-851 \mathrm{c}$ allele than in the other group of patients $\left(p=0.04\right.$, likelihood ratio $\chi^{2}$, odds ratio $\left.=2.4\right)$.

Conlusion: TNF $\alpha$ polymorphisms are associated with the severity of CF lung disease in Czech and Belgian patients with $\mathrm{CF}$.
C ystic fibrosis (CF) is a common lethal autosomal recessive disease affecting the white population with an incidence of about 1 in $2500 .{ }^{12}$ Certain phenotypes of CF are clearly associated with different CF transmembrane conductance regulator (CFTR) genotypes such as pancreatic insufficiency, but pulmonary disease is strongly influenced by other factors. ${ }^{3}$ There are many genes that may affect the CF phenotype. These genes may affect secondary symptoms, such as genes encoding proteins involved in lung defence (immune system, inflammation processes, protection against oxidative stress) or genes encoding proteins which directly or indirectly interact with CFTR. Phenotypic differences among patients with the same CFTR genotype are most likely caused by differences in the function of such proteins and/or by environmental factors. Previous studies have shown an association between variant alleles and the severity of the CF phenotype-for example, it was found that polymorphisms in the mannose binding lectin (MBL) protein, which result in low or no functional MBL, contribute to more severe CF lung disease. ${ }^{45}$

Tumour necrosis factor $\alpha(\mathrm{TNF} \alpha)$, an endogenous factor of the lung involved in host defence, ${ }^{6}$ is therefore a possible modulator of CF pulmonary disease severity. TNF $\alpha$ is a proinflammatory cytokine largely produced by macrophages, ${ }^{7}$ whose gene is located on chromosome 6p21.3. ${ }^{8}$ It is prothrombotic, promotes leucocyte adhesion and migration, modulates haematopoiesis and lymphocyte development, induces other cytokines, and has an important role in macrophage activation and the immune response in tissues. Even though there are many polymorphisms in the promoter region of $\mathrm{TNF} \alpha$, much attention has been given to the $\mathrm{TNF} \alpha$ $-308 \mathrm{~g} / \mathrm{a}$ polymorphic locus. In a previous study of CF patients from a UK CF clinical centre, an association was found between the $-308 a$ allele and a more severe CF phenotype. ${ }^{10}$ A modulating role of a genetic factor with disease, based on association studies, should however only be treated as tentative until the finding of an association has been replicated in other studies. Moreover, we broadened the search with additional polymorphisms for an association between TNF $\alpha$ and severity of lung function in CF patients. We therefore investigated whether the TNF $\alpha-308 \mathrm{~g} / \mathrm{a}$ polymorphic locus, together with the $-851 \mathrm{c} / \mathrm{t},-238 \mathrm{~g} / \mathrm{a}$ promoter polymorphic loci and the polymorphic locus $+691 \mathrm{~g}$ ins/del in intron $1^{11}$, are associated with pulmonary function, body mass index (BMI), and susceptibility to Pseudomonas aeruginosa infection in Belgian and Czech patients with CF.

\section{METHODS}

\section{Study subjects}

Only CF patients homozygous for the F508del CFTR mutation were included in the study in order to exclude variability in CF disease because of the CFTR genotype. 180 patients with CF were recruited to the study, 58 from the Belgium University Hospital Gasthuisberg and 122 from the Czech Republic CF Center Prague University Hospital Motol. The control population comprised 85 healthy adult blood donors

Abbreviations: CF, cystic fibrosis; CFTR, cystic fibrosis transmembrane conductance regulator; $\mathrm{FEV}_{1}$, forced expiratory volume in 1 second; $\mathrm{MBL}$, mannose binding lectin; TNF $\alpha$, tumour necrosis factor $\alpha$ 
from Belgium and 63 healthy adult blood donors and 55 newborn infants from the Czech Republic. Controls were ethnically matched to patients.

For Hardy-Weinberg equilibrium testing, all unrelated CF patients were included. For the actual association study of TNF $\alpha$ polymorphisms with the CF pulmonary phenotype, only 113 CF patients (41 Belgian and 72 Czech) between the ages of 12 and 15 years (mean age 13.4) were included; $49 \%$ were male. Indeed, a modulating gene may only become penetrant by age so it will only be detected in association studies using a well defined group of CF patients of a particular age or age range. All clinical data were retrieved from the patients' case records. The BMI was measured and percentage predicted values of forced expiratory volume in 1 second $\left(\mathrm{FEV}_{1}\right)$ were calculated according to Knudson et al. ${ }^{12}$ Statistical analysis of lung function was performed on the last $\mathrm{FEV}_{1} \%$ predicted value between the ages of 12 and 15 years.

The age of first infection with $P$ aeruginosa was available from the case records of 119 of the total group of 180 CF patients. Patients were followed at the outpatient clinic at a minimum of 3 monthly intervals. At every visit, sputum samples (or throat swabs in patients who did not expectorate) were taken. The age at which $P$ aeruginosa was isolated for the first time is referred to as first infection with $P$ aeruginosa.

The association studies were approved by the ethical committees of both universities.

\section{PCR and single nucleotide extension assay}

We developed multiplex single nucleotide primer extension assays in which the TNF $\alpha$ single nucleotide polymorphisms (SNPs) were included. This study is part of a much larger study involving semi-high throughput analysis of tens of SNPs, so gap filling experiments were needed for the samples in which a genotype could not be obtained for the first time. However, from a practical point of view, complete gap filling is not possible in such a large study because the DNA of some samples becomes exhausted. Thus, the number of genotypes/ alleles obtained for each SNP may differ between different SNPs. For the single nucleotide primer extension assay, the SNP detection kit (SNaPshot; Applied Biosystems) was used. The primers used for amplification of the genomic regions covering the SNPs in TNF $\alpha$ and the single nucleotide extension oligonucleotides are shown in tables S1 and S2 respectively, available on the Thorax website at http:// www.thoraxjnl.com/supplemental.

\section{Statistical analysis}

Database management and statistical analysis were performed with the SAS statistical package release 8.01 (SAS Institute Inc, Cary, NC, USA) and the SYSTAT package release 7.0 (SPSS Inc, Chicago, IL, USA). Statistical tests were considered significant when their type I error was less than 0.05. Differences between the mean $\mathrm{FEV}_{1} \%$ predicted values of Czech and Belgian populations were assessed using a twosample $t$ test after checking whether the variances of the populations were equal or not. Comparison between one independent and one dependent qualitative variables were assessed using the $\chi^{2}$ likelihood ratio test or by the Fisher exact probability test when more than $20 \%$ of the cells had an expected count of less than 5. When the independent variables were qualitative and the dependent one was quantitative, a parametric analysis of variance (ANOVA) was done. Pearson's correlation coefficient was calculated to test the goodness of fit of one independent quantitative value and one dependent quantitative value in a linear regression model.

\section{RESULTS}

The TNF $\alpha$ promoter polymorphic loci $-238 \mathrm{~g} / \mathrm{a},-308 \mathrm{~g} / \mathrm{a}$, $-851 \mathrm{c} / \mathrm{t}$ and the TNF $\alpha$ intron 1 polymorphic locus $+691 \mathrm{~g}$ ins/ del were typed in $180 \mathrm{CF}$ patients and 203 controls. We tested for the possibility of population stratification because of differences in ethnicity, age, and sex but found no significant differences. Furthermore, no differences were found between the Belgian and Czech cohorts with regard to the distribution of alleles/genotypes (see table S3 available on the Thorax website at http://www.thoraxjnl.com/supplemental), mean FEV $_{1}$ (68.9\% for Belgian patients and $68.4 \%$ for Czech patients, $\mathrm{p}=0.91$, mean difference $0.5 \%, 95 \%$ CI -9.3 to 8.3, two-sample $t$ test), and mean $\mathrm{FEV}_{1} \%$ for each genotype $(-308 \mathrm{~g} / \mathrm{a}: \mathrm{p}=0.7 \mathrm{l},-85 \mathrm{lc} / \mathrm{t}: 0.83$, and $+69 \mathrm{lg}$ ins/del: $\mathrm{p}=0.65$, ANOVA), so the data from the two populations were merged. In the combined groups there was no significant difference in allele and genotype frequencies between all $\mathrm{CF}$ patients compared with all controls (table S3).

$\mathrm{FEV}_{1} \%$ predicted values of CF patients decline with age ${ }^{13}$ and females have a steeper decline in pulmonary function than males. ${ }^{14} \mathrm{FEV}_{1} \%$ predicted values calculated according to Knudson are corrected for sex and age. ${ }^{12}$ Nevertheless, we determined whether the $\mathrm{FEV}_{1} \%$ predicted values were truly independent of sex and age in our age selected cohort of patients and found no influence of age (Pearson correlation coefficient $r^{2}=0.006$ ) or sex ( $\mathrm{p}=0.21$, mean difference $5.4 \%$, $95 \% \mathrm{CI}-13.7$ to 3.0, two-sample $t$ test) on $\mathrm{FEV}_{1} \%$ predicted.

We then determined whether the values of $\mathrm{FEV}_{1} \%$ predicted in CF patients were dependent on the distribution of TNF $\alpha$ genotypes. Given that a modifier effect may only become penetrant by age, as has been shown for MBL2, ${ }^{5}{ }^{15}$ only CF patients aged 12-15 years were included in the actual association study. The mean $\mathrm{FEV}_{1} \%$ of the age selected cohort of CF patients was approximately $70 \%$ predicted, so patients with an $\mathrm{FEV}_{1}$ less than $70 \%$ predicted were compared with those with an $\mathrm{FEV}_{1}$ of more than $70 \%$ predicted. The distribution of $+691 \mathrm{~g}$ ins/del was found to be significantly different between the two groups, with a higher proportion of those in whom the $\mathrm{FEV}_{1}$ was more than $70 \%$ predicted being heterozygous for the two alleles at the $+691 \mathrm{~g}$ ins/del locus (table 1). More importantly, the mean $\mathrm{FEV}_{1} \%$ predicted values differed significantly between the two groups, patients with the $+691 \mathrm{~g}$ ins/+69lg del genotype having a higher mean $\mathrm{FEV}_{1} \%$ predicted value than those with the $+691 \mathrm{~g}$ ins/+691g ins genotype (table 2). Both these tests were significant even when a conservative Bonferroni correction (correction for multiple testing for four SNPs) was performed.

The distribution of $-851 c / t$ genotypes did not differ significantly between patients with $\mathrm{FEV}_{1}$ values above and below $70 \%$ predicted (table 1). However, in a dominant/ recessive model, a significantly higher proportion of patients with an $\mathrm{FEV}_{1}$ lower than $70 \%$ predicted were homozygous for the $-851 \mathrm{c}$ allele than in the other group of patients (table 1). The mean $\mathrm{FEV}_{1} \%$ predicted values were not significantly different between the three genotypes of $-851 c / t$ separately or in a dominant/recessive model (table 2).

The $-308 \mathrm{~g} / \mathrm{a}$ and $-238 \mathrm{~g} / \mathrm{a}$ polymorphic loci were not significantly associated with $\mathrm{FEV}_{1}$ values above or below $70 \%$ predicted (table 1 ). Also, the mean $\mathrm{FEV}_{1} \%$ predicted values were not significantly different between the three genotypes, separately or in a dominant/recessive model, for $-308 \mathrm{~g} / \mathrm{a}$ or $-238 \mathrm{~g} / \mathrm{a}$ (table 2 ).

Records of the age at first onset of $P$ aeruginosa infection were available for 119 patients with CF. We examined whether the age of first infection with $P$ aeruginosa was associated with SNP alleles or genotypes in TNF $\alpha$ and found that $+691 \mathrm{~g}$ ins $/+691 \mathrm{~g}$ ins homozygotes were colonised with $P$ aeruginosa at a significantly earlier age than 


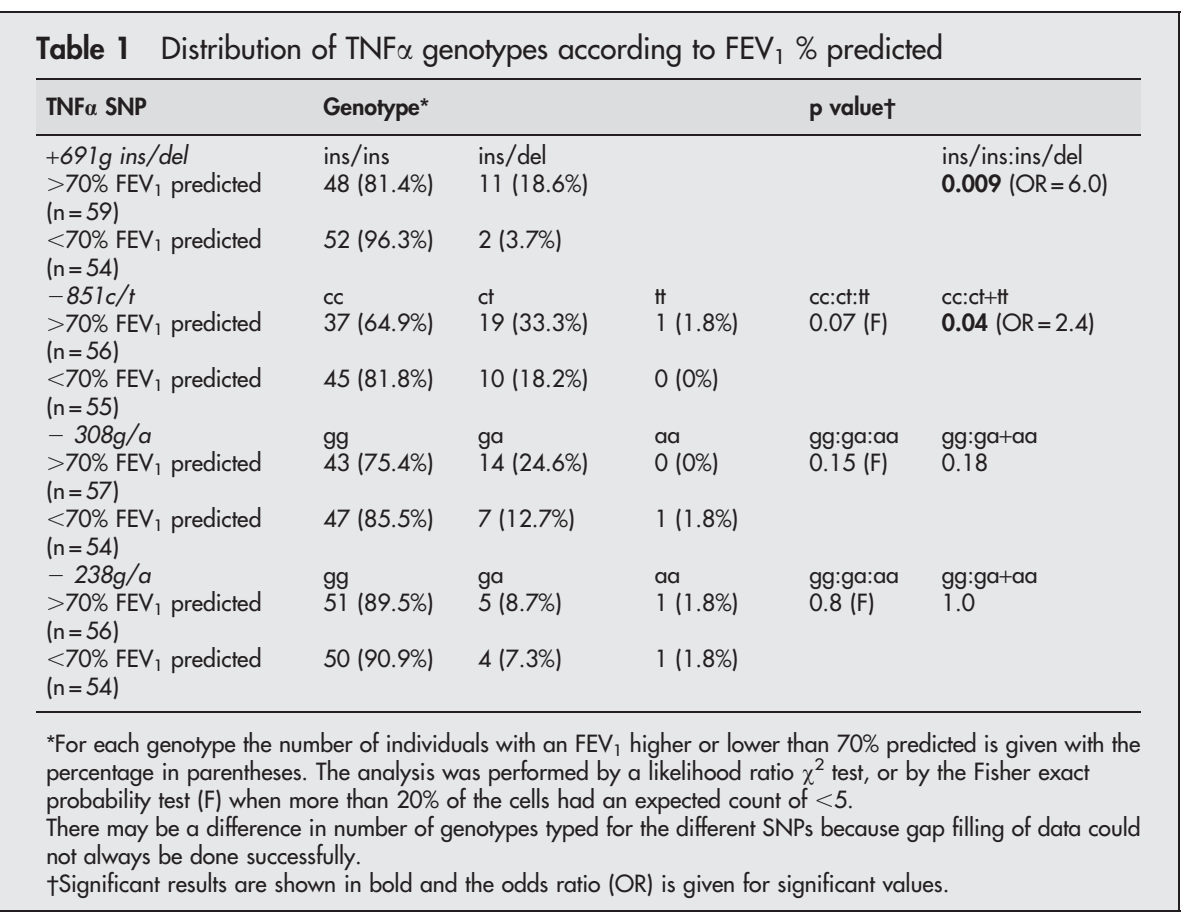

$+691 \mathrm{~g}$ ins $/+691 \mathrm{~g} \mathrm{del} \mathrm{heterozygotes} \mathrm{(table} 3$ ). The mean first age of infection with $P$ aeruginosa for the $+691 \mathrm{~g}$ ins/del genotypes did not differ between the Belgian and Czech CF cohorts $(p=0.21$, ANOVA), indicating that there was no skewing to either of the two centres. No other variants were significantly associated with the first age of infection with $P$ aeruginosa when the genotypes were tested separately or in a dominant/ recessive model.

We also tested whether the BMI of the age selected cohort of patients was associated with SNP alleles or genotypes in TNF $\alpha$. None of the TNF $\alpha$ variants was significantly associated with the BMI of these patients (see table S4 available on the Thorax website at http://www.thoraxjnl.com/supplemental).

\section{DISCUSSION}

The patients in this study were derived from two white European populations. We decided to group the patients in order to strengthen the statistical power of the study. In order to exclude variables that might affect the phenotype, the following precautions were taken. Only patients homozygous for the F508 deletion in the CFTR gene were included in order to exclude an effect of the CFTR genotype on disease. Patients were included from only two centres in order to exclude variability in treatment which might affect disease status and the measurement of clinical parameters of the patients. Only patients between 12 and 15 years of age were studied. It is important to neutralise age variability because a modulating genetic factor may only become penetrant by age, ${ }^{5}$ which can only be detected in studies in age selected groups of patients. Furthermore, $\mathrm{FEV}_{1} \%$ predicted values of patients with $\mathrm{CF}$ decline more rapidly with age than in the general population, ${ }^{13}$ and therefore may interfere with results when testing pulmonary function as a dependent of genotype distribution. The fact that $\mathrm{FEV}_{1} \%$ values did not differ with the age of the patients in the present cohort of age selected patients supports the credibility of the chosen age group. We also determined whether we could compare the disease severity between subjects without the influence of sex since female $\mathrm{CF}$ patients are known to have significantly lower $\mathrm{FEV}_{1} \%$ predicted values than males. ${ }^{14}$ No significant difference in sex corrected $\mathrm{FEV}_{\mathrm{I}} \%$ values between male and female patients were seen in our cohort of age selected patients. The frequencies of the tested alleles/genotypes and $\mathrm{FEV}_{1} \%$ predicted values were not significantly different between the two populations, allowing us to group the patient populations together. All genotype distributions were in Hardy-Weinberg equilibrium except for $-238 \mathrm{~g} / \mathrm{a}$ in the total Czech patient subgroup. A technical artefact is unlikely, given the fact that this marker was in Hardy-Weinberg equilibrium for all control groups and the Belgian patients with CF. Since the Hardy-Weinberg disequilibrium is only observed in the Czech CF patients and not the Czech controls, and since it is caused by the presence of two homozygotes for the -238 a allele instead of the expected 0 to 1 homozygote, it is possible

Table 2 Differences in mean $\mathrm{FEV}_{1} \%$ predicted values according to TNF $\alpha$ genotypes

\begin{tabular}{|c|c|c|c|c|c|}
\hline \multirow{2}{*}{$\begin{array}{l}\text { TNF } \alpha \text { SNP } \\
+691 \mathrm{~g} \text { ins/del }\end{array}$} & \multicolumn{2}{|c|}{ Mean (SD) $\mathrm{FEV}_{1}(\%$ predicted)* } & \multirow[t]{2}{*}{ Mean difference } & $95 \% \mathrm{Cl}$ & $\mathrm{p}$ valuet \\
\hline & $\begin{array}{l}\text { ins/ins }(n=100) \\
67.5(23.0)\end{array}$ & $\begin{array}{l}\text { ins/del }(n=13) \\
79.7(12.8)\end{array}$ & & 3.5 to 21.0 & 0.008 \\
\hline$-851 c / t$ & $c c(n=82)$ & $\mathrm{ct}+\mathrm{Ht}(\mathrm{n}=30)$ & & & \\
\hline & $66.9(23.6)$ & $72.6(20.2)$ & 5.7 & -15.3 to 4.0 & 0.25 \\
\hline$-308 g / a$ & $g g(n=90)$ & $g a+a a(n=22)$ & & & \\
\hline & $66.9(22.7)$ & $74.8(22.4)$ & 7.9 & -2.8 to 18.6 & 0.15 \\
\hline & $68.2(22.4)$ & $70.4(27.6)$ & 2.2 & -16.6 to 21.1 & 0.8 \\
\hline
\end{tabular}

*The analysis was performed by a two sample $t$ test. There may be a difference in the number of genotypes/alleles typed for the different SNPs because gap filling of data could not always be done successfully. †Significant results are shown in bold. 


\begin{tabular}{|c|c|c|c|c|c|}
\hline \multirow{3}{*}{$\begin{array}{l}\text { TNF } \alpha \text { SNP } \\
+691 \mathrm{~g} \text { ins } / \text { del }\end{array}$} & \multicolumn{2}{|c|}{$\begin{array}{l}\text { Mean (SD) first age of infection } \\
\text { with } P \text { aeruginosa }\end{array}$} & \multirow{3}{*}{$\begin{array}{l}\begin{array}{l}\text { Mean } \\
\text { difference }\end{array} \\
3.1\end{array}$} & \multirow{3}{*}{$\begin{array}{l}95 \% \mathrm{Cl} \\
0.5 \text { to } 5.6\end{array}$} & \multirow{3}{*}{$\frac{p \text { valuet }}{0.018}$} \\
\hline & ins/ins ( $n=103)$ & ins/del $(n=16)$ & & & \\
\hline & $\begin{array}{l}8.3(4.6) \\
\operatorname{cc}(n=88)\end{array}$ & $\begin{array}{l}11.4(6.0) \\
\mathrm{ct+Ht}(n=27)\end{array}$ & & & \\
\hline$-851 c / t$ & $\begin{array}{l}8.6(4.8) \\
g g(n=89)\end{array}$ & $\begin{array}{l}9.2(4.3) \\
\text { ga+aa }(n=27)\end{array}$ & 0.5 & -2.6 to 1.5 & 0.60 \\
\hline$-308 g / a$ & $\begin{array}{l}8.5(4.5) \\
g g(n=104)\end{array}$ & $\begin{array}{l}9.5(5.2) \\
\text { ga+aa }(n=12)\end{array}$ & 1.0 & -1.1 to 3.0 & 0.37 \\
\hline$-238 g / a$ & $8.8(4.4)$ & $7.9(6.6)$ & 0.9 & -5.2 to 3.3 & 0.64 \\
\hline
\end{tabular}

that the Hardy-Weinberg disequilibrium was observed because of the small sample size. The mean $\mathrm{FEV}_{1}$ of the age selected cohort of CF patients in the current study is approximately $70 \%$ predicted, so patients with an $\mathrm{FEV}_{1}$ of less than $70 \%$ predicted were compared with those having an $\mathrm{FEV}_{1}$ higher than $70 \%$ predicted. We found an altered distribution of two TNF $\alpha$ polymorphisms depending on pulmonary function. Specifically, the presence of the $+691 \mathrm{~g}$ del allele was more likely to be associated with better pulmonary function and $-851 \mathrm{c}$ homozygotes were found to be associated with worse pulmonary function than $-851 \mathrm{c} /-851 t+-851 t /-851 t$ CF patients. In our cohort of CF patients the $-308 \mathrm{~g} / \mathrm{a}$ and the $-238 \mathrm{~g} / \mathrm{a}$ polymorphic loci were not associated with severity of pulmonary disease. It should be noted that the functional consequences of these polymorphisms on TNF $\alpha$ are not known; however conflicting results have been found for the $-308 a$ allele, which has been associated with increased levels of TNF $\alpha$ and the $-238 a$ allele which has been associated with lower levels of TNF $\alpha$, although others have found that $-308 a$ and $-238 a$ do not affect the levels of TNF $\alpha .^{16-18}$

Apart from the association of $+691 \mathrm{~g}$ del with better CF pulmonary function, this variant was also significantly associated with an older first recorded/observed age of infection with $P$ aeruginosa. The most common pulmonary infection in the lungs of patients with CF is $P$ aeruginosa, ${ }^{19}$ and progression of lung disease unequivocally accelerates after colonisation with this organism. ${ }^{20}$ Therefore, the younger the first age of infection with $P$ aeruginosa, the more rapid the decline in pulmonary function. Mucoid $P$ aeruginosa is a key factor in accelerating the decline in pulmonary function in

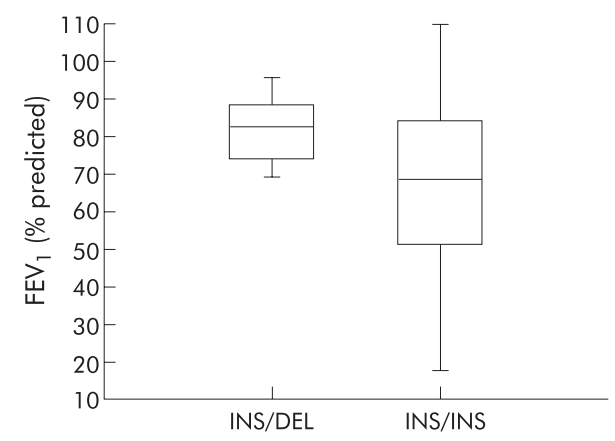

Figure 1 Box plot showing median $\mathrm{FEV}_{1}$ percentage predicted values with $25-75 \%$ quartiles. The mean (SD) FEV $1 \%$ predicted values of $C F$ patients with the $+691 \mathrm{~g}$ ins $/$ del TNF $\alpha$ genotype $(79.7(12.8) \%, n=13)$ and those with the $+691 \mathrm{~g}$ ins/ins TNF $\alpha$ genotype $(67.5(23.0) \%$, $\mathrm{n}=100)$ were significantly different $(\mathrm{p}=0.008$, two-sample $t$ test). patients with $\mathrm{CF}^{21} \mathrm{TNF} \alpha$ plays an important role in the innate resistance to $P$ aeruginosa and its clearance from the respiratory tract. ${ }^{22}{ }^{23}$ Polymorphisms in the TNF $\alpha$ gene may lead to changes in levels of $\mathrm{TNF}^{16}$ which may, in turn, increase the ability of the lung to clear $P$ aeruginosa. On the other hand, increased concentrations of TNF $\alpha$ have been found in lung secretions of CF patients ${ }^{74}$ which may contribute directly to neutrophil influx and elastase activity that eventually destroy the CF lung. ${ }^{7}$ Furthermore, if a certain $\mathrm{TNF} \alpha$ allele has a quantitative or qualitative effect on the TNF $\alpha$ protein, it would most likely have a knock on effect on the secretion and synthesis of other members of the cytokine cascade. ${ }^{9}$ There is probably a balance between its activity in protecting the immune system against pathogens and its destructive side effects. It is feasible that this balance may be tipped in one or other direction when a patient has a certain polymorphic variant in an important mediator of the immune system such as the TNF $\alpha$ gene. Interestingly, the variability in $\mathrm{FEV}_{1} \%$ predicted values in patients with the $+69 \mathrm{lg}$ del variant is small and in the mild range, but not the most mild (fig 1). This may be due to the balance between the beneficial and detrimental properties of the TNF $\alpha$ protein.

The $+691 \mathrm{~g}$ ins/del SNP was not associated with the BMI in the age selected cohort of patients; however, analogous to the results for $\mathrm{FEV}_{1} \%$ predicted and age of first infection with $P$ aeruginosa, patients with the $+691 \mathrm{~g}$ del allele tended to have a slightly better BMI than those homozygous for the $+691 \mathrm{~g}$ ins allele.

Both variants of the $+691 \mathrm{~g}$ ins/del and $-851 \mathrm{c} / \mathrm{t}$ polymorphic loci were found to be associated with the degree of severity of CF disease. Variants of the $+691 \mathrm{~g}$ ins/del locus were associated with the severity of CF lung disease in three separate tests. In contrast to $+691 \mathrm{~g}$ ins $/$ del, $-851 \mathrm{c} / \mathrm{t}$ was associated with pulmonary function in only one test and was not associated with pulmonary defence. The association of $+691 \mathrm{~g}$ ins $/$ del variants with the severity of CF pulmonary disease therefore seems to be more important than the $-851 \mathrm{c} / \mathrm{t}$ variants. Of course, it is possible that these observed associations with CF disease severity are caused by another mutation in linkage disequilibrium, either in this gene or in neighbouring genes. In this regard, $\mathrm{TNF} \alpha$ alleles have been shown to be in linkage disequilibrium with HLA alleles-for example, $+691 \mathrm{~g}$ del is linked to $\mathrm{DRB}^{*} 11^{*} 13$ and $\mathrm{DQB} 1^{*} 301 .^{25}$

In a previous study by Hull and Thomson ${ }^{10}$ in which an association was found between the $-308 a$ allele and a more severe CF phenotype, no other TNF $\alpha$ polymorphisms were tested. There have also been a number of investigations into the possible association of the TNF $\alpha-308 \mathrm{~g} / \mathrm{a}$ polymorphic locus with susceptibility to chronic obstructive pulmonary disease, but their conclusions were conflicting. ${ }^{26}$ In the present study no significant association was found between 
$-308 \mathrm{~g} / \mathrm{a}$ polymorphic variants and severity of CF disease. Furthermore, we found that the $-308 \mathrm{~g}$ allele tended to be associated with more severe CF disease, although not significantly. Possible explanations for these dissimilar results might be explained by the fact that we selected only F508del homozygotes in order to exclude disease variability because of the CFTR genotype, while Hull and Thomson ${ }^{10}$ included patients who were either F508del homozygotes or heterozygotes. Also, we tested more than twice as many patients, and our patients were all aged between 12 and 15 years with a mean age of 13.4 years compared with the previous study where the patients were all aged 8 years.

The allele frequencies of the TNF $\alpha$ polymorphisms in this study were very similar to those found among French controls by Herrmann et al. ${ }^{11}$ In that study, six different haplotypes from these polymorphisms could be constructed. One haplotype contained the $+691 \mathrm{~g}$ del allele, the $-851 \mathrm{c}$ allele, and the $-308 \mathrm{a}$ allele. The $+691 \mathrm{~g}$ del allele is only observed on this haplotype while the $-308 a$ allele appears on this haplotype and an additional haplotype. ${ }^{26}$ This may explain the conflicting data of the association of TNF $\alpha-308 a$ in CF lung disease in the study by Hull and Thomson, ${ }^{10}$ and possibly the association of TNF $\alpha-308 a$ in COPD. ${ }^{27-30}$ Indeed, it is feasible that only one of the two haplotypes on which -308 a resides is the causal one, but which of them cannot be discriminated when typing the $-308 \mathrm{~g} / \mathrm{a}$ SNP alone. This might also explain why several studies have found that the rare $-308 a$ allele is associated with increased levels of TNF $\alpha$ while others have found that $-308 a$ does not affect levels of TNF $\alpha .{ }^{16}$

Our findings might be of interest from a pharmacogenetic point of view. Our results show that particular polymorphic $\mathrm{TNF} \alpha$ loci are associated with better lung function. Antiinflammatory agents are currently being used for the treatment of $\mathrm{CF}^{31}$-for example, ibuprofen was found to reduce the rate of decline in $\mathrm{FEV}_{1}$ values in CF patients under 13 years of age. ${ }^{32}$ Since ibuprofen seems to lessen the effects of $\mathrm{TNF},{ }^{33}$ it may be important to determine the genotype of TNF $\alpha$ polymorphic variants of a patient before deciding on treatment with anti-inflammatory agents. Indeed, administration of such drugs to CF patients may be of therapeutic value in some patients but detrimental in others, based on the TNF $\alpha$ genotype. It should be noted that ibuprofen was not administered to any of the Belgian CF patients in this study but it was given to six Czech CF patients $(+691 \mathrm{~g}$ ins homozygotes) for a few weeks only.

In conclusion, we did not find any evidence that the $-308 \mathrm{~g} / \mathrm{a} \mathrm{TNF} \alpha$ polymorphic locus is associated with CF lung disease in Belgian and Czech patients with CF. However, our results indicate an involvement of TNF $\alpha$ in the modulation of CF disease since the $+691 \mathrm{~g}$ ins/del and $-851 \mathrm{c} / \mathrm{t}$ loci are associated with lung disease severity. Functional studies are needed to confirm this association and to unravel the mechanism of modulation.

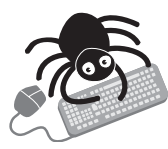

Further data on the primers used for amplification of the genomic regions covering the SNPs in TNF $\alpha$ and the single nucleotide extension oligonucleotides (tables $\mathrm{S} 1$ and S2 respectively), the distribution of alleles/ genotypes in the Belgian and Czech cohorts (table S3), and the association of TNF $\alpha$ variants with BMI (table S4) are available on the Thorax website at http:// www.thoraxinl.com/supplemental.

\footnotetext{
Authors' affiliations

J Yarden , D Radojkovic, R Vlietinck, J-J Cassiman , H Cuppens, Department for Human Genetics, KULeuven, Herestraat 49, O\&N6, 3000 Leuven, Belgium
}

D Radojkovic , Institute of Molecular Genetics and Genetic Engineering, Vojvode Stepe 444a, Belgrade, Serbia and Montenegro

K De Boeck, Department of Pediatrics, UZ Gasthuisberg, Herestraat 49, 3000 Leuven, Belgium

M Macek Jr, D Zemkova, V Vavrova , Charles University Prague and University Hospital Motol, V Uvalu 84, CZ 15006 Prague, Czech Republic

These investigations were supported by a CF-PRONET (QLG1-CT-200101005) grant from the European Commission, an Interuniversity Poles of Aftraction Program (P5/25-H) grant, grant (GOA 99/07) from the Onderzoeksraad KU Leuven, grant Alphonse and Jean Forton-Koning Boudewijn Stichting (2000 14 R71 15 B0), grant 1417 from the Ministry of Science and Technology, Republic of Serbia, MZ CR-00000064203, 6464-3 and MSMT CR-LNOOA079, 111300003 . J-J Cassiman is holder of the Arthur Bax and Anna Vanluffelen Chair of Human Genetics.

\section{REFERENCES}

1 Welsh MJ, Tsui L-C, Boat TF, et al. Cystic fibrosis. In: Scriver CR, Beaudet AL, Sly WS, et al. The metabolic and molecular basis of inherited disease. 7th ed. Vol 3. New York: McGrawHill, 1995:3799-876.

2 Sheppard DN, Welsh MJ. Structure and function of the CFTR chloride channel. Physiol Rev 1999:79:S23-45.

3 Santis G, Osborne L, Knight RA, et al. Independent genetic determinants of pancreatic and pulmonary status in cystic fibrosis. Lancet 1990;336:1081-4.

4 Garred P, Pressler T, Madsen HO, et al. Association of mannose-binding lectin gene heterogeneity with severity of lung disease and survival in cystic fibrosis. J Clin Invest 1999;104:431-7.

5 Yarden J, Radojkovic D, De Boeck K, et al. Polymorphisms in the mannose binding lectin gene affect the CF pulmonary phenotype. J Med Genet 2004:41:629-33.

6 de Boer WI. Cytokines and therapy in COPD: a promising combination? Chest 2002;121(Suppl 5):S209-18.

7 Bonfield T, Panuska J, Konstan M, et al. Inflammatory cytokines in cystic fibrosis lungs. Am J Respir Crit Care Med 1995;152:2111-8.

8 Spies T, Morton CC, Nedospasov SA, et al. Genes for the tumor necrosis factors alpha and beta are linked to the human major histocompatibility complex. Proc Natl Acad Sci USA 1986;83:8699-702.

9 Roitt I, Brostoff J, Male D. Immunology, 6th ed. London: Mosby, 2001.

$10 \mathrm{Hull}$ J, Thomson AH. Contribution of genetic factors other than CFTR to disease severity in cystic fibrosis. Thorax 1998;53:1018-21.

11 Herrmann SM, Ricard S, Nicaud V, et al. Polymorphisms of the tumour necrosis factor-alpha gene, coronary heart disease and obesity. Eur J Clin Invest 1998;28:59-66.

12 Knudson RJ, Lebowitz MD, Holberg CJ, et al. Changes in the normal maximal expiratory flow-volume curve with growth and aging. Am Rev Respir Dis 1983;127:725-34

13 Corey $M$, Edwards $\mathrm{L}$, Levison $\mathrm{H}$, et al. Longitudinal analysis of pulmonary function decline in patients with cystic fibrosis. J Pediatr 1997;131:809-14

14 Davis PB. The gender gap in cystic fibrosis survival. J Gend Specif Med 1999;2:47-51.

15 Davies JC, Johnson M, Booth C, et al. Age-specific effect of the cystic fibrosis modifier gene, MBL-2. Pediatr Pulmonol Suppl 2002;24:223-3.

16 Hajeer AH, Hutchinson IV. Influence of TNFalpha gene polymorphisms on TNFalpha production and disease. Hum Immunol 2001;62:1191-9.

17 Pociot F, D'Alfonso S, Compasso S, et al. Functional analysis of a new polymorphism in the human TNF alpha gene promoter. Scand J Immunol 1995:42:501-4.

18 Huizinga TW, Westendorp RG, Bollen EL, et al. TNF-alpha promoter polymorphisms, production and susceptibility to multiple sclerosis in different groups of patients. J Neuroimmunol 1997;72:149-53.

19 Ratien F, Doring G. Cystic fibrosis. Lancet 2003;361:681-9.

20 Kosorok MR, Zeng L, West SE, et al. Acceleration of lung disease in children with cystic fibrosis after Pseudomonas aeruginosa acquisition. Pediatr Pulmonol 2001;32:277-87.

21 Parad RB, Gerard CJ, Zurakowski D, et al. Pulmonary outcome in cystic fibrosis is influenced primarily by mucoid Pseudomonas aeruginosa infection and immune status and only modestly by genotype. Infect Immun 1999;67:4744-50.

22 Yu H, Nasr SZ, Deretic V. Innate lung defenses and compromised Pseudomonas aeruginosa clearance in the malnourished mouse model of respiratory infections in cystic fibrosis. Infect Immun 2000;68:2142-7.

23 Harder J, Meyer-Hoffert U, Teran LM, et al. Mucoid Pseudomonas aeruginosa, TNF-alpha, and IL-1 beta, but not IL-6, induce human betadefensin-2 in respiratory epithelia. Am J Respir Cell Mol Biol 2000;22:714-21.

24 Osika E, Cavaillon JM, Chadelat K, et al. Distinct sputum cytokine profiles in cystic fibrosis and other chronic inflammatory airway disease. Eur Respir J 1999:14:339-46.

25 Low AS, Azmy l, Sharaf N, et al. Association between two tumour necrosis factor intronic polymorphisms and HLA alleles. Eur J Immunogenet 2002;29:31-4.

26 Joos L, Pare PD, Sandford AJ. Genetic risk factors of chronic obstructive pulmonary disease. Swiss Med Wkly 2002;132:27-37.

27 Sakao S, Tatsumi K, Igari H, et al. Association of tumor necrosis factor alpha gene promoter polymorphism with the presence of chronic obstructive pulmonary disease. Am J Respir Crit Care Med 2001;163:420-2. 
28 Keatings VM, Cave SJ, Henry MJ, et al. A polymorphism in the tumor necrosis factor-alpha gene promoter region may predispose to a poor prognosis in COPD. Chest 2000;118:971-5

29 Higham MA, Pride NB, Alikhan A, et al. Tumour necrosis factor-alpha gene promoter polymorphism in chronic obstructive pulmonary disease. Eur Respir J 2000; 15:281-4.

30 Ishii T, Matsuse T, Teramoto S, et al. Neither IL-1 beta, IL-1 receptor antagonist, nor TNF-alpha polymorphisms are associated with susceptibility to COPD. Respir Med 2000;94:847-51.
31 Konstan MW, Davis PB. Pharmacological approaches for the discovery and development of new anti-inflammatory agents for the treatment of cystic fibrosis. Adv Drug Deliv Rev 2002;54:1409-23.

32 Konstan MW, Byard PJ, Hoppel CL, et al. Effect of high-dose ibuprofen in patients with cystic fibrosis. N Engl J Med 1995:332:848-54.

33 Zapolska-Downar D, Naruszewicz M, Zapolski-Downar A, et al. Ibuprofen inhibits adhesiveness of monocytes to endothelium and reduces cellular oxidative stress in smokers and non-smokers. Eur J Clin Invest $2000 \cdot 30: 1002-10$

\section{LUNG ALERT}

Surfactant replacement does not reduce duration of ventilatory support in paediatric acute lung injury

$\Delta$ Willson DF, Thomas NJ, Markovitz BP, et al. Effect of exogenous surfactant (Calfactant) in pediatric acute lung injury: a randomized controlled trial. JAMA 2005;293:470-6

he quality and composition of surfactant are abnormal in acute lung injury. In adult

patients surfactant replacement has had little effect on outcomes, but preliminary

studies in paediatric patients have supported further research. The importance of the constitution of the administered surfactant is increasingly being recognised. Calfactant is a modified bovine surfactant that closely resembles endogenous surfactant in composition and function.

This study is a randomised controlled trial in American paediatric intensive care units (ICU) with all patients receiving a protective ventilation strategy. The study was designed to recruit 300 patients in 2 years. The number of ventilator free days in the 28 days following study entry, a marker of the duration of respiratory failure, was the primary outcome. Because of difficulties recruiting adequate numbers of patients, the trial ended after 3 years with 152 patients randomised. Patients were randomised to two doses of intratracheal Calfactant or air placebo.

There was no difference in primary outcome between the groups (mean (SD) ventilator free days 13.2 (10) in the treatment group and 11.5 (10.5) in the placebo group; $p=0.21$ ). However, while the study was not powered to detect a mortality difference, mortality was reduced in the Calfactant group (15/77 patients versus 27/75, OR 2.32, 95\% CI 1.15 to 4.85 ) and oxygenation also improved after treatment. No patient was removed because of treatment complications.

This study failed to show a difference in duration of mechanical ventilation in paediatric ICU patients, but was underpowered and illustrates the difficulties in recruiting adequate patient numbers even to well designed trials in ICU.

A MacDuff

SHERT Clinical Research Fellow, MRC Centre for Inflammation Research, Edinburgh University, Edinburgh, UK; andrew.macduff@ed.ac.uk 